\title{
Oral supplementation with omega-3 fatty acids and inflammation markers in patients with chronic kidney disease in hemodialysis
}

\author{
José A. Valle Flores, Juan E. Fariño Cortéz, Gabriel A. Mayner Tresol, Juan Perozo Romero, \\ Miquel Blasco Carlos, and Teresa Nestares
}

\begin{abstract}
Chronic kidney disease (CKD) is an increasingly common public health problem that increases the risk of death because of cardiovascular complications by 2-3 times compared with the general population. This research concerns a prospective, randomized, double-blind study in patients with CKD undergoing hemodialysis. The participants were assigned to 1 of 2 groups: the study group (group A; 46 patients) received 4 capsules $(2.4 \mathrm{~g})$ of omega-3 fatty acids daily during the 12-week intervention, while patients in the control group (group B; 47 patients) received 4 capsules of paraffin oil. The patients' general characteristics, nutritional indicators, renal disease markers and inflammatory markers (C-reactive protein, interleukin (IL)-6, IL-10, and tumour necrosis factor alpha (TNF- $\alpha)$ ) were evaluated. No differences were found between the general characteristics of the patients $(P<0.05)$, and no differences were shown in the nutritional indicators and markers of kidney disease $(P<0.05)$. Patients in group A showed significant decreases in levels of C-reactive protein, IL-6, TNF- $\alpha$, and the IL-10/IL-6 ratio after 12 weeks of supplementation $(P<0.05)$. Patients in group B did not show any significant changes in concentrations of inflammatory markers during the intervention $(P<0.05)$. In conclusion, oral supplementation with omega-3 fatty acids produces a significant decrease in the concentrations of inflammation markers in patients with chronic kidney disease on hemodialysis.
\end{abstract}

Novelty

- Oral supplementation with omega-3 fatty acids produced significant decreases in the concentrations of inflammation markers.

- This supplementation could be given to patients with uremic syndrome and coronary heart disease to reduce cardiovascular risk.

Key words: chronic kidney disease, C-reactive protein, interleukin-6, interleukin-10, hemodialysis, nutritional assessment, tumour necrosis factor alpha, omega-3 fatty acids, supplementation.

Résumé : La maladie du rein chronique ("CKD ») est un problème de santé publique de plus en plus courant qui augmente de 2 à 3 fois, chez les patients aux prises avec cette maladie, le risque de décès dû aux complications cardiovasculaires comparativement à la population générale. Cette recherche est une étude prospective, randomisée, en double insu chez des patients atteints de CKD subissant une hémodialyse. Les participants sont répartis dans l'un des deux groupes: le groupe d'étude (groupe A, 46 patients) reçoit quatre capsules (2,4 g) d'acides gras oméga-3 par jour au cours de l'intervention de 12 semaines et les patients du groupe témoin (groupe B, 47 patients) reçoivent quatre capsules d'huile de paraffine. Les caractéristiques générales des patients, les indicateurs nutritionnels, les marqueurs des maladies rénales et les marqueurs inflammatoires (protéine C-réactive, interleukine ( IL »-6, IL-10 et facteur de nécrose tumorale alpha (« TNF- $\alpha$ ») sont évalués. Aucune différence n'est observée entre les caractéristiques générales des patients $(P<0,05)$ et aucune différence n'apparait dans les indicateurs nutritionnels et les marqueurs de la maladie rénale $(P<0,05)$. Après 12 semaines de supplémentation, les patients du groupe A présentent une diminution significative des niveaux de protéine C-réactive, d'IL-6, de TNF- $\alpha$ et du ratio IL-10/IL-6 $(P<0,05)$. Les patients du groupe $B$ ne présentent aucun changement significatif des concentrations de marqueurs inflammatoires pendant l'intervention $(P<0,05)$. En conclusion, une supplémentation orale en acides gras oméga-3 produit une diminution significative des concentrations de marqueurs de l'inflammation chez les patients atteints d'une maladie du rein chronique et sous hémodialyse. [Traduit par la Rédaction]

Received 3 October 2019. Accepted 2 January 2020.

J.A. Valle Flores. Nutrition and Food Science Program, University of Granada, Spain; Nutrition and Dietetics, Faculty of Medical Sciences, Universidad Católica de Santiago de Guayaquil, Guayaquil, Ecuador, 150950.

J.E. Fariño Cortéz. Carrera de Enfermería, Facultad de Ciencias Sociales y de la Salud, Universidad Estatal de Santa Elena, Santa Elena, Ecuador, 241702.

G.A. Mayner Tresol. Carrera de Medicina, Facultad de Ciencias Médicas, Universidad Católica de Santiago de Guayaquil, Guayaquil, Ecuador, 150950.

J. Perozo Romero. Servicio de Nefrología, Hospital Central Dr. Urquinaona, Facultad de Medicina, Universidad de Zulia, Maracaibo, Venezuela, 4001.

M. Blasco Carlos. Instituto de Investigación e Innovación de Salud Integral, Universidad Católica de Santiago de Guayaquil, Avenue Carlos Julio Arosemena

Tola, Guayaquil, Ecuador; Escuela de Nutrición y Dietética, Universidad Espíritu Santo-Ecuador, Avenue Samborondón, Guayaquil, Ecuador.

T. Nestares. Department of Physiology, Institute of Nutrition and Food Technology, University of Granada, Granada, Spain, 18010.

Corresponding author: José A. Valle Flores (emails: drvallef@gmail.com, josevallef@correo.ugr.es).

Copyright remains with the author(s) or their institution(s). Permission for reuse (free in most cases) can be obtained from copyright.com. 


\section{Les nouveautés}

- La supplémentation orale en acides gras oméga-3 suscite une diminution significative des concentrations de marqueurs de l'inflammation.

- Cette supplémentation pourrait être administrée aux patients atteints de syndrome urémique et de maladie coronarienne pour réduire le risque cardiovasculaire.

Mots-clés : maladie du rein chronique, protéine C-réactive, interleukine-6, interleukine-10, hémodialyse, évaluation nutritionnelle, facteur de nécrose tumorale alpha, acides gras oméga-3, supplémentation.

\section{Introduction}

Chronic kidney disease (CKD) is an increasingly common public health problem that increases the risk of death from cardiovascular diseases by $2-3$ times compared with the general population. This is because the inflammatory response, mediated by cytokines, chemokines, and other molecules, leads to increased oxidative stress and tissue damage, resulting in an increased risk of cardiac mortality (Wakasugi et al. 2016). Patients with kidney disease undergoing hemodialysis have an even higher risk of mortality (Sabry et al. 2014). Chronic inflammatory status can be assessed by determining the concentrations of various serum biomarkers, such as C-reactive protein (CRP), interleukin (IL)-6, IL-10, and tumour necrosis factor alpha (TNF- $\alpha$ ) (Krintus et al. 2014). These markers allow an estimation of the severity of inflammation and the therapeutic response in patients with CKD undergoing hemodialysis (Calder 2017).

One potential therapy is supplementation with omega-3 longchain polyunsaturated fatty acids. Omega- 3 fatty acids are mainly obtained from dietary sources, especially fish oil, and they are an important component of a healthy diet. They may also have therapeutic utility in patients at high risk of inflammatory and cardiovascular diseases (Abdelhamid et al. 2018) since they can modify several risk conditions; specifically, they can modify the atherogenic risk profile and decrease arterial hypertension, oxidative stress, and inflammation (Hall 2017). This may be due to their ability to act in multiple key biological processes, such as eicosanoid production, cell membrane physiology, metabolic pathway signalling, and expression/regulation of the activity of several genes (Watkins et al. 2016).

Various studies indicate that patients with CKD have significantly lower blood levels of omega-3 fatty acids than the general population, probably because of lower food intake as well as to inflammation, nutrient malabsorption, and metabolic changes (Rasic-Milutinovic et al. 2007). Moreover, hemodialysis can affect the bioavailability of omega- 3 fatty acids, since patients undergoing hemodialysis may have increased oxidative stress, which reduces concentrations of omega-3 fatty acids (Rivara et al. 2015). However, another report states that the effects of supplementation in patients with CKD are independent of hemodialysis (Fassett et al. 2010).

Despite its potential for the treatment of various pathologies mediated by inflammation, omega- 3 fatty acid supplementation is not routinely used in patients with CKD, possibly because of ignorance of its possible therapeutic effects. Yet in recent decades, there has been a growing scientific interest in the potential benefits of supplementation with these fatty acids, and several clinical trials have investigated the effects in patients with CKD undergoing hemodialysis. Some of these studies have shown that oral supplementation with omega-3 fatty acids lowers the concentrations of IL-6, TNF- $\alpha$, and CRP in patients undergoing hemodialysis (Ewers et al. 2009), while other researchers have not found any significant effects on these markers in similar groups of patients (Hassan et al. 2010). In view of this contradiction, the objective of this investigation is to establish the effects of oral omega-3 fatty acid supplementation on inflammation markers in patients with CKD on hemodialysis.

\section{Materials and methods}

\section{Study design and population}

This study was prospective, randomized, double-blinded, and placebo-controlled with 2 parallel arms in adult patients diagnosed with CKD and undergoing hemodialysis. All participants were selected from patients treated in the nephrology office of the Central and University Hospitals in Maracaibo, Venezuela, during the period from January 2018 to June 2019. The ethics committee of the hospital approved the study protocol and consent was obtained in writing from each participant after informing them of the research objectives in relation to the effect of omega-3 fatty acid supplementation on inflammatory markers. The study was registered in the Registry of Clinical Studies (registration no. 2019001-0053).

Patient inclusion criteria were glomerular filtration rate $<10 \mathrm{~mL} /\left(\mathrm{min} \cdot 1.73 \mathrm{~m}^{2}\right)$, age over 18 years, body mass index (BMI) of $20-30 \mathrm{~kg} / \mathrm{m}^{2}$, regular hemodialysis in the 6 months prior to the beginning of the study, and willingness to take part in the research. All selected participants had hemodialysis sessions lasting 3-4 h, three times a week, with a low flow dialyzer and using sodium bicarbonate as a buffer. The hemodialysis procedure remained unchanged during the study period.

Patients with active inflammatory/infectious disease, a history of peritoneal dialysis, a diagnosis of malignant tumours, chronic obstructive pulmonary disease, hyperthyroidism, hemoglobinopathies, coagulopathies, malabsorption syndrome, surgeries in the last 6 months, or noncompliance with the hemodialysis program were excluded. In addition, patients who consumed anticoagulant, lipid-lowering, beta-blocker, L-carnitine, corticosteroid, immunosuppressive, and/or immunomodulatory drugs as well as those with evidence of regular consumption of antioxidant vitamins foods rich in omega-3 fatty acids and/or fish oil 6 months prior to the start of the study, a hypersensitivity/intolerance to fish products, or noncompliance with the treatment (consumption of less than $70 \%$ of the supplement) were also excluded.

The sample size was calculated according to the CRP values (Iqbal et al. 2015). According to a previous study conducted in patients with CKD on hemodialysis, a difference of $4 \mathrm{mg} / \mathrm{L}$ was found between the groups, with a standard deviation of $2 \mathrm{mg} / \mathrm{mL}$. Based on this information, the minimum sample size for each group was 45 participants, with an estimated power of $80 \%$ and $\alpha=0.05$ to detect a $15 \%$ change in concentrations. Considering the possibility of dropouts and exclusions, the size for each group was established as 56 eligible patients. Participants remained in their assigned treatment groups regardless of postassignment withdrawal.

A list of computer-generated random numbers was used in a block randomization scheme to ensure 2 randomly selected participant groups of similar sizes. The numbers were stored in sealed envelopes and numbered by independent staff. Participants in the study group (group A) received 4 capsules of omega-3 fatty acids daily during the 12 weeks of intervention. Each capsule contained $360 \mathrm{mg}$ of eicosapentaenoic acid and $240 \mathrm{mg}$ of docosahexaenoic acid. This omega-3 dose was administered according to accepted international standards (Bossola et al. 2013). Patients in the control group (group B) received 4 capsules containing 
Table 1. Composition of fatty acids of the omega-3 and placebo capsules.

\begin{tabular}{lll}
\hline & $\begin{array}{l}\text { Omega-3 capsules, } \\
\text { g/100 g as fatty acids }\end{array}$ & $\begin{array}{l}\text { Placebo capsules, } \\
\text { g/g as fatty acids }\end{array}$ \\
\hline C16:0 & 0.96 & 13.86 \\
C16:1 & 0.35 & 1.44 \\
C17:0 & 0.14 & 0.07 \\
C17:1 & - & 0.11 \\
C18:0 & 4.66 & 2.73 \\
C18:1n9 & 8.88 & 66.64 \\
C18:2n6 & 2 & 11.42 \\
C18:3n3 & 0.77 & 0.69 \\
C20:0 & 0.5 & 0.43 \\
C20:1n9 & - & 0.26 \\
C20:5n3 & 35.36 & - \\
C21:5n3 & 1.7 & - \\
C22:5n3 & 4.95 & - \\
C22: 6n3 & 24.31 & - \\
Saturated fatty acids & 7.02 & 17.26 \\
Monounsaturated fatty acids & 15.21 & 70.63 \\
Polyunsaturated fatty acids & 77.77 & 12.11 \\
Omega-3 & 67.08 & 0.69 \\
\hline
\end{tabular}

paraffin oil. These contained the standard ingredients of soft gelatin capsules (gelatin, water, glycerin, and vitamin $\mathrm{E}$ in minute amounts as a preservative). An analysis of the capsules, which were provided by an independent laboratory, is presented in Table 1 . The appearance (shape, size, and colour) of the capsules used in both groups was identical. The capsules were divided by groups, placed in sealed envelopes by a person who was independent to the study, and delivered once a week following one of the hemodialysis sessions. Throughout the study, all participants, treating doctors, and researchers were unaware of the patients' group assignments.

\section{Assessment of patients' functional states}

The clinical, biochemical, and functional status data for each participant were obtained at the beginning of the study and after the 12 weeks of intervention. The usual diet of each patient was evaluated using a single 72 -h reminder interview and then analyzed by 2 nutritionists, who were part of the research team but did not know which treatment group each subject belonged to, using the Food Processing and Nutrition Analysis Program (Esha Research, USA). The participants were found to have a low consumption of soy foods, a once-weekly fish intake, and no dietary supplement of oil rich in long-chain fatty acids. The participants were asked to continue with their normal eating habits (35 kcal/kg body weight, protein intake $1.0-1.2 \mathrm{~g} / \mathrm{kg}$ body weight, and fat $<35 \%$ of caloric intake with a sodium restriction of $60-100 \mathrm{mEq} /$ day and a potassium restriction of 50-100 $\mathrm{mEq} /$ day) according to the Clinical Practice Guidelines K-DOQI, the pharmacological regime, and their physical activity (less than $1 \mathrm{~h}$ per week) during the study period. For all participants, functional evaluations were conducted on a regular basis by means of interviews during hemodialysis sessions. Antihypertensive treatment was used to maintain blood pressure values of less than $160 / 90 \mathrm{~mm} \mathrm{Hg}$.

Patients' weight was measured with an approximation of $0.1 \mathrm{~kg}$ using a calibrated electronic digital scale while patients were barefoot and wearing light clothing. Height was measured with an accuracy of $0.1 \mathrm{~cm}$, using a portable stadiometer that had a nonelastic tape and was mounted to the wall, while patients were barefoot with heels touching the ground and eyes directed forward. Both measurements were made in the 20 min following the end of the hemodialysis session and always by the same duly trained person. The average of 3 successive measurements of body weight before the start and end of the study period was used to assess body weight. BMI was calculated and expressed as $\mathrm{kg} / \mathrm{m}^{2}$.
The quality of dialysis was measured for each subject before and after the study period according to serum urea nitrogen concentrations before and after dialysis, ultrafiltration volume, dialysis time, and weight after dialysis using the equation of Leypoldt et al. (2004).

Compliance with supplementation was evaluated twice a week by one of the researchers who was unaware of the randomization of the participants and using the conventional practice of "pill counting", based on the known number of capsules given to the patient at their last interview and the counted number of unused capsules that the patient returned to the clinic. An intake exceeding $70 \%$ of the prescribed capsules during the study period was considered to be adequate compliance. Any change in medications during the study period was recorded.

\section{Biochemical tests and trials}

Blood samples $(20 \mathrm{~mL})$ were taken from each patient before and after the 12 weeks of intervention and were obtained after a 12-h night fast and immediately before the hemodialysis session. The samples were stored in sterile tubes containing EDTA to separate the serum. All samples were centrifuged immediately at $3500 \mathrm{rpm}$ $(\mathrm{RCF}=5000)$ for $10 \mathrm{~min}$. The serum was then separated, divided into aliquots, and subsequently stored at $-70{ }^{\circ} \mathrm{C}$ for subsequent determination of inflammatory markers. CRP concentrations were determined by a turbidimetric method with intra- and inter-assay variability coefficients of $8 \%$ and $9 \%$, respectively (Diagnostics Biochem Canada Inc., London, Ont., Canada). The concentrations of IL- 6 , TNF- $\alpha$, and IL-10 were measured in duplicate with immunoassays (Immunotech, Beckman Coulter, USA). These measurements had intra- and inter-assay variability coefficients of $8 \%$ and $10 \%$, respectively. Functional status was evaluated by determining serum albumin concentrations using the green colorimetric method of bromocresol (Autoanalyzer BT3000, Biotechnica, Italy). Routine tests for the follow-up of hemodialysis patients (creatinine, urea, urea nitrogen, uric acid, hemoglobin, glucose, phosphorus, calcium, potassium, and sodium) were also conducted on these samples at the beginning and end of the study in the hospital laboratory according to automated standard procedures.

\section{Statistical analysis}

The data were analyzed using a statistical program for social sciences, SPSS Statistics for Windows version 22 (IBM Corp., Armonk, N.Y., USA). The categorical data were presented as absolute values and percentages, while the continuous data were presented as means and SD. All quantitative data were analyzed to determine normality using the Kolmogrov-Smirnov test and the Shapiro-Wilk test. A $t$ test was used for related samples and the Mann-Whitney test was used to determine the differences in the variables of interest between the 2 groups at the beginning and at the end of the study. Fischer's exact test was used to compare the categorical variables between both groups. Differences in quantitative variables between the groups were analyzed using the $t$ test for unrelated samples or the Kruskal-Wallis test during the 12-week intervention period. The value of $P \leq 0.05$ was considered statistically significant.

The study was conducted according to the World Medical Association's Declaration of Helsinki. The patients gave their written informed consent, and this consent and the study protocol were approved by approved by the Venezuelan committee on human research in Maracaibo (the Comité de Ética en Investigación of the Ministerio del Poder Popular para la Salud).

\section{Results}

A total of 124 patients were selected for the investigation, of which 102 were eligible to take part in the trial. After randomization, 19 patients (10 in group A and 9 in group B) were excluded from the final analysis because of losses during follow-up, which 
Fig. 1. Flowchart of patient participation during the study.
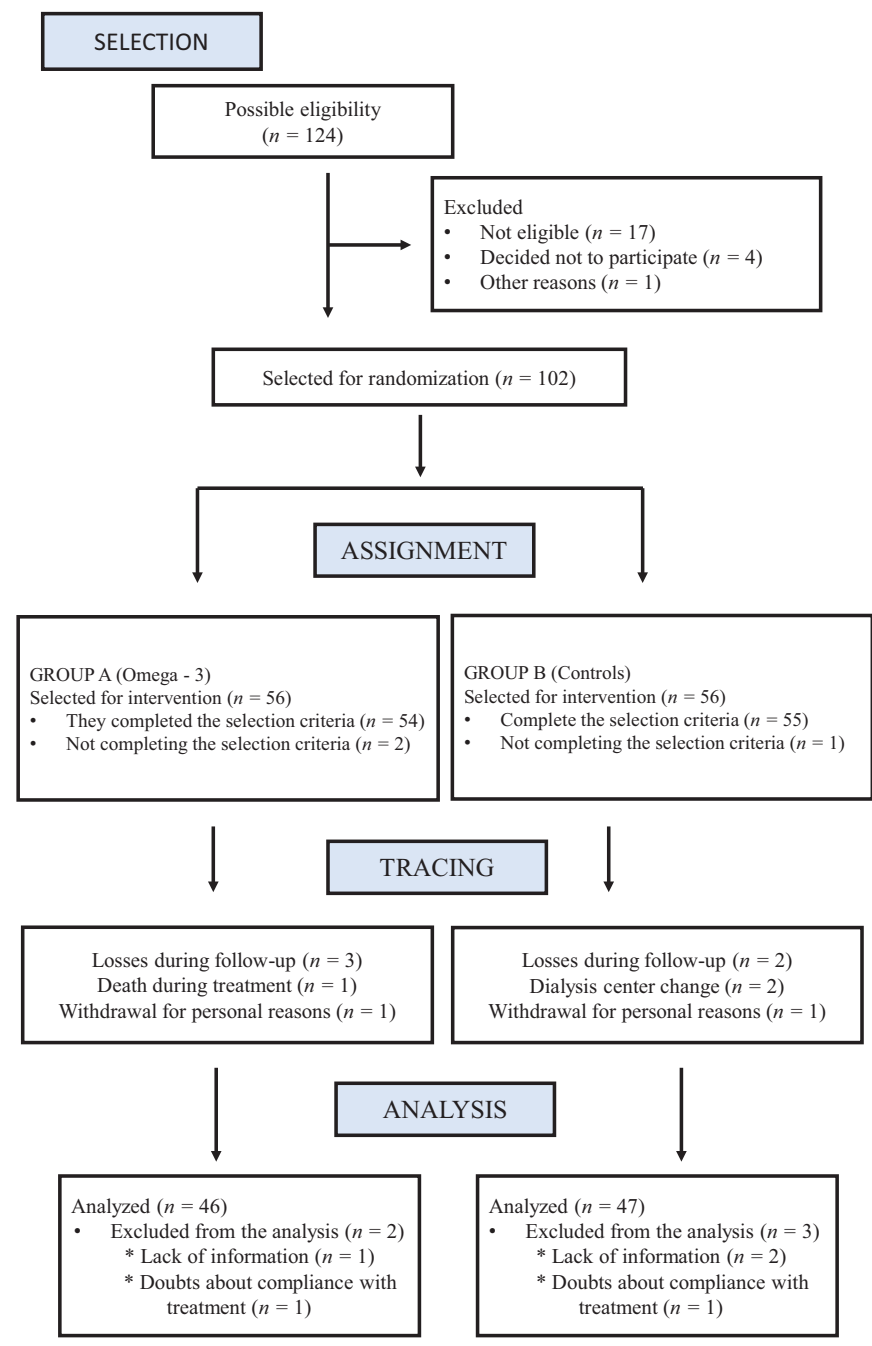

included death, withdrawal for personal reasons, change of dialysis centre, and a lack of provided information or lack of responses to questions about compliance with the treatment. The flowchart of patient participation during the study is presented in Fig. 1. Therefore, for the final analysis, the data of the 46 patients assigned to be treated with omega- 3 fatty acids (group A) and the 47 patients assigned to the control group (group B) were used.

Table 2 shows the general characteristics of the patients in both groups. The mean (SD) age of the patients in group A was 52.1(8.2) years and in group B it was 49.6 (8.3) years. The differences between the groups were not significant $(P=0.15)$. Most patients in both treatment groups were male $65.2 \%$ in group A and $68.1 \%$ in group B). No significant difference was found between the groups in relation to the frequency by sex $(P=0.83)$. The BMI and the average duration of hemodialysis were also similar in both study groups ( $P=0.21$ and $P=0.57$, respectively). Furthermore, no significant differences were found between the groups in the frequency of history of dyslipidemia, statin use, hypertension, diabetes, smoking, and use of erythropoietin $(P \geq 0.05)$.

Table 3 shows the functional indicators and disease markers for each of the groups before and after treatment. In group A, no significant differences were observed in the body mass index and hemodialysis quality before and after the 12 weeks of treatment with omega- 3 fatty acids $(P=0.36$ and $P=0.32)$. Also, no significant differences were found in the values of hemoglobin, albumin, creatinine, urea, uric acid, sodium, glycemia, potassium, phosphorus, and calcium during the study period $(P \geq 0.05)$. The pa-
Table 2. General characteristics of both patient groups.

\begin{tabular}{lllr}
\hline & $\begin{array}{l}\text { Group A } \\
\text { cases, } n=46\end{array}$ & $\begin{array}{l}\text { Group B } \\
\text { control, } n=47\end{array}$ \\
\hline Age, y & $52.1(8.2)$ & $49.6(8.3)$ & 0.15 \\
Sex, $n$ (\%) & & & \\
$\quad$ Male & $30(65.2)$ & $32(68.1)$ & 0.83 \\
$\quad$ Female & $16(34.8)$ & $15(31.9)$ & \\
Body mass index, kg/m ${ }^{2}$ & $21.1(1.8)$ & $21.6(2.0)$ & 0.21 \\
Hemodialysis time, mo & $56.5(17.8)$ & $54.6(14.5)$ & 0.57 \\
History of dyslipidemia, $n(\%)$ & $34(73.9)$ & $33(70.2)$ & 0.82 \\
History of statin use, $n(\%)$ & $24(52.1)$ & $21(44.7)$ & 0.54 \\
History of hypertension, $n(\%)$ & $22(47.8)$ & $17(36.2)$ & 0.30 \\
History of diabetes, $n(\%)$ & $17(36.9)$ & $13(27.7)$ & 0.38 \\
History of smoking habit, $n(\%)$ & $5(10.8)$ & $6(12.8)$ & 10.00 \\
Erythropoietin use, $n(\%)$ & $44(95.7)$ & $41(87.2)$ & 0.26 \\
\hline
\end{tabular}

Note: Values are means (SD) unless otherwise specified.

tients in group B also showed no differences in these functional indicators or in markers of renal disease after the study period compared with their initial values $(P \geq 0.05)$. These differences in indicators and markers between both study groups after 12 weeks of treatment were considered not significant $(P \geq 0.05)$.

When analyzing the variations in the concentrations of inflammatory markers in both groups of patients (Table 4), a significant decrease in CRP concentrations (-26.08\%) was observed during the 12 weeks of oral supplementation with omega-3 fatty acids $(P \leq 0.001)$. This finding was accompanied by decreases in the concentrations of IL-6 (-25.06\%) and TNF- $\alpha$ (-13.13\%). Both decreases were considered statistically significant $(P \leq 0.001$ and $P=0.009$, respectively). IL-10 concentrations also increased during the 12-week intervention period $(+12.21 \%)$; however, this change was not considered significant $(P=0.27)$. On the other hand, the IL-10/IL-6 ratio increased significantly $(+41.65 \% ; P \leq 0.001)$, and while the IL-10/TNF- $\alpha$ ratio increased $(+16.08 \%)$, it was not significant $(P=0.12)$. In the patients of group $B$, no differences were found in the final values compared with the initial values of the inflammation markers $(P \geq 0.05)$. Overall, statistically significant differences between group A and group B were observed in the markers of inflammation and in the relationships between the interleukins $(P \leq 0.05)$ after 12 weeks of treatment.

\section{Discussion}

The research results clearly show that oral omega-3 supplementation causes a decrease in the concentrations of CRP, IL-6, and TNF- $\alpha$ in patients with CKD on hemodialysis. In addition, serum IL-10 concentrations showed significant variations related to the comparison of both study groups (patients receiving supplements and the control group), but no significant differences were found within them. These findings suggest that omega-3 fatty acids exerted a beneficial effect through the reduction of inflammation markers in this group of patients.

Inflammation is a common characteristic of patients with CKD, whether undergoing hemodialysis or not. High concentrations of inflammation markers enhance oxidative stress, which leads to increased cardiovascular risk (Dai et al. 2017). There is evidence that the progress of CKD is associated with low-grade inflammation, even in patients with moderate renal impairment who are not undergoing hemodialysis. This suggests that increased concentrations of CRP, IL- 6 , and TNF- $\alpha$ are related to the severity of the disease (Memoli et al. 2002). Some researchers have shown that low concentrations of inflammatory markers improve survival in patients with CKD (Memoli et al. 2010; Šulović 2017). Therefore, the modulation of inflammation in these patients can slow the progression of the disease.

Previous investigations, both in vitro and in vivo, have shown that omega-3 fatty acids can modify different aspects of the inflammation process (Moertl et al. 2011). The mechanism by which 
Table 3. Variations of the functional indicators and markers of kidney disease between groups before and after treatment.

\begin{tabular}{|c|c|c|c|c|c|c|c|c|c|}
\hline \multirow[b]{2}{*}{ Average \pm SD } & \multicolumn{4}{|c|}{ Group A cases $(n=46)$} & \multicolumn{4}{|c|}{ Group B control $(n=47)$} & \multirow[b]{2}{*}{$\begin{array}{l}P \text { between group } \mathrm{A} \\
\text { and group } \mathrm{B}\end{array}$} \\
\hline & $\begin{array}{l}\text { Before the } \\
\text { treatment }\end{array}$ & $\begin{array}{l}\text { After the } \\
\text { treatment }\end{array}$ & $\begin{array}{l}\text { Percentage } \\
\text { exchange }\end{array}$ & $P$ & $\begin{array}{l}\text { Before the } \\
\text { treatment }\end{array}$ & $\begin{array}{l}\text { After the } \\
\text { treatment }\end{array}$ & $\begin{array}{l}\text { Percentage } \\
\text { exchange }\end{array}$ & $P$ & \\
\hline Body mass index, kg/m² & $21.1(1.8)$ & $21.5(2.0)$ & 1.89 & 0.36 & $21.8(2.0)$ & $21.1(2.0)$ & 3.21 & 0.93 & 0.34 \\
\hline Hemoglobin, $\mathrm{g} / \mathrm{dL}$ & $10.1(1.2)$ & $9.9(1.1)$ & 1.98 & 0.41 & $9.9(1.1)$ & $10.2(1.0)$ & 3.03 & 0.17 & 0.17 \\
\hline Albumin, g/dL & $4.00(0.20)$ & $3.98(0.23)$ & 0.50 & 0.66 & $4.03(0.23)$ & $3.96(0.32)$ & 1.73 & 0.23 & 0.68 \\
\hline Creatinine, mg/dL & $10.1(2.3)$ & $10.0(2.2)$ & 1.00 & 0.83 & $9.6(2.3)$ & $10.3(2.3)$ & 7.29 & 0.14 & 0.52 \\
\hline Glycemia, mg/dL & $101.3(25.2)$ & $96.8(22.6)$ & 4.44 & 0.37 & $100.2(25.8)$ & $101.3(25.6)$ & 1.09 & 0.84 & 0.37 \\
\hline Sodium, mEq/L & $131.9(1.2)$ & $131.8(1.3)$ & 0.7 & 0.70 & $131.8(1.1)$ & $132.1(1.0)$ & 0.22 & 0.17 & 0.22 \\
\hline Potassium, mEq/L & $5.5(0.3)$ & $5.4(0.4)$ & 1.81 & 0.18 & $5.4(0.4)$ & $5.5(0.3)$ & 1.85 & 0.17 & 0.18 \\
\hline Phosphorus, mEq/L & $8.70(0.30)$ & $8.59(0.29)$ & 1.26 & 0.08 & $8.68(0.29)$ & $8.70(0.22)$ & 0.8 & 0.19 & 0.06 \\
\hline Calcium, mEq/L & $4.2(0.4)$ & $4.1(0.5)$ & 2.38 & 0.29 & $4.1(0.3)$ & $4.2(0.4)$ & 2.43 & 0.17 & 0.29 \\
\hline
\end{tabular}

Note: Values are means (SD). kt/v, quality of dialysis.

Table 4. Variations in the concentrations of inflammation markers before and after treatment.

\begin{tabular}{|c|c|c|c|c|c|c|c|c|c|}
\hline \multirow[b]{2}{*}{ Average \pm SD } & \multicolumn{4}{|c|}{ Group A cases, $n=46$} & \multicolumn{4}{|c|}{ Group B control, $n=47$} & \multirow[b]{2}{*}{$\begin{array}{l}\mathrm{P} \text { between group } \mathrm{A} \\
\text { and group } \mathrm{B}\end{array}$} \\
\hline & $\begin{array}{l}\text { Before the } \\
\text { treatment }\end{array}$ & $\begin{array}{l}\text { After the } \\
\text { treatment }\end{array}$ & $\begin{array}{l}\text { Percentage } \\
\text { exchange }\end{array}$ & $P$ & $\begin{array}{l}\text { Before the } \\
\text { treatment }\end{array}$ & $\begin{array}{l}\text { After the } \\
\text { treatment }\end{array}$ & $\begin{array}{l}\text { Percentage } \\
\text { exchange }\end{array}$ & $P$ & \\
\hline IL-6, mg/mL & $72.9(24.4)$ & $53.9(14.9)$ & 25.06 & $<0.001$ & $71.1(26.1)$ & $68.8(25.4)$ & 3.23 & 0.67 & $<0.001$ \\
\hline TNF- $\alpha, \mathrm{mg} / \mathrm{mL}$ & $67.0(13.9)$ & $58.2(12.4)$ & 13.13 & 0.002 & $69.4(14.3)$ & $69.1(14.9)$ & 0.43 & 0.93 & $<0.001$ \\
\hline $\mathrm{IL}-10, \mathrm{pg} / \mathrm{mL}$ & 117.9 (42.1) & $132.3(47.0)$ & 12.21 & 0.27 & $114.7(37.6)$ & $112.1(38.9)$ & 0.55 & 0.74 & 0.03 \\
\hline Relationship IL-10/IL-6 & $1.80(0.87)$ & $2.55(1.13)$ & 41.65 & $<0.001$ & $1.89(1.08)$ & $1.95(1.16)$ & 4.27 & 0.80 & 0.01 \\
\hline
\end{tabular}

Note: Values are means (SD). IL, interleukin; TNF- $\alpha$, tumor necrosis factor alpha.

they exert their anti-inflammatory effects can be through protein kinase, activated by AMPk through a protein called silent information regulator 1 , which leads to the deacetylation of the nuclear factor kappa B (NF- $\mathrm{B}$ ), is stimulated by proinflammatory agents such as cytokines and CRP. The activation of NF- $\mathrm{B}$ and mononuclear cells triggers a process that culminates with myocardial inflammatory damage in patients undergoing hemodialysis (Wang et al. 2017). It has also been shown that arachidonic acid can be competitively inhibited by decreasing the conversion of proinflammatory intermediates (Inoue et al. 2017). In addition, because the fatty acids present in the cell membrane play an important role in signal transduction, omega- 3 fatty acids can modify gene expression (Calder 2015).

This study contributes to a body of existing research that has found potential therapeutic benefits to omega-3 supplementation for CKD patients on dialysis through the reduction of inflammation. Several of these previous studies have described results such as the attenuation of dyslipidemia and inflammation (decreased CRP and IL-6 concentrations). Others have found that omega-3 fatty acids produce a significant decrease in CRP concentrations in Cree adults (aged 18-91 years) (Labonte et al. 2014). It has also been shown that omega-3 fatty acids decrease inflammatory markers concentrations in patients with both chronic diseases and diabetic neuropathy (Han et al. 2016). A study examining oral supplementation with $1.3 \mathrm{~g} /$ day of omega-3 fatty acids daily for 3 months found a decrease in CRP concentrations (Saifullah et al. 2007). An investigation in patients with CKD and hemodialysis treated with $3 \mathrm{~g} /$ day of omega-3 fatty acids for 3 months showed a significant reduction in CRP and IL-6 concentrations (Tayyebi-Khosroshahi et al. 2012). Another study that used $1800 \mathrm{mg} /$ day for 4 months reported a significant reduction in CRP and IL-6 concentrations (Gharekhani et al. 2014).

In contrast with the findings of this study, other papers have failed to show a reduction in inflammation by supplementing omega-3 for CKD patients. Besides, in 1 study, using a dose of $2.08 \mathrm{~g} /$ day for 10 weeks found no decrease in concentrations of systemic inflammatory and oxidative stress markers (Kooshki et al. 2011). However, other research has not shown that omega-3 fatty acids have a significant effect on inflammatory markers in patients with CKD (Hassan et al. 2010). On the other hand, in another study that evaluated the effects of omega-3 fatty acids ( $3.4 \mathrm{~g} /$ day for 1 year) in patients receiving heart transplants, the patients in the treatment group presented increased concentrations of TNF- $\alpha$ and decreased concentrations of IL-10, suggesting a pro-inflammatory effect (Holm et al. 2001).

This investigation also contributes to a body of work reporting that omega- 3 fatty acid supplementation reduces TNF- $\alpha$ concentrations significantly in patients undergoing hemodialysis (Tayyebi-Khosroshahi et al. 2012). For example, in a study that used $2.4 \mathrm{~g} /$ day supplementation for 8 weeks in patients with CKD and hemodialysis, a significant decrease in TNF- $\alpha$, IL-6, CRP, and ferritin concentrations was observed (Leypoldt et al. 2004). It is possible for omega-3 to produce these results because they are a type of polyunsaturated fatty acids that can also decrease the production of classic proinflammatory cytokines as well as adhesion molecules involved in the inflammatory response. A significant increase in the values of the IL-10/IL-6 ratio compared with a placebo was also observed in this study. Therefore, omega-3 fatty acid supplementation acts as protection against the negative effects of IL- 6 and TNF- $\alpha$ (Magee et al. 2012).

The afore mentioned contradictory results of previous studies evaluating the effects of omega-3 fatty acid supplementation on inflammation markers in patients with CKD may arise from several different factors. Possible explanations for the differences observed include duration of treatment, sample size, and the reference values of inflammatory markers. In addition, the dose and duration of supplementation should be considered, since higher doses over a longer period could decrease the concentrations of CRP, IL-6, TNF- $\alpha$, and other inflammatory markers in patients with CKD who are undergoing hemodialysis on a regular basis (Fiedler et al. 2005). Another consideration would be related to the background of the selected patients in each study, which may 
alter the results of the investigations. Finally, the duration and severity of inflammation should also be taken into account, especially in those patients undergoing hemodialysis.

In this investigation, serum albumin concentrations, one of the markers of functional status, showed no changes during the treatment period in the group of patients treated with omega-3 fatty acids, which is similar to previously reported results (Sarav and Friedman 2018). Reduced protein intake and increased inflammatory response are 2 important factors that lead to a decrease in serum albumin (Barle et al. 2006). In addition, one previous study showed that low serum albumin concentrations in dialysis patients may be caused by systemic inflammation rather than nutritional insufficiency. Other authors suggest that serum albumin should be considered as a marker of disease rather than nutrition (Donadio et al. 2012). BMI, dialysis efficiency, and markers of kidney disease also showed no change during the treatment period in this study, either when comparing the values before and after treatment or when comparing the final values of the groups of cases and controls. Similar results have been previously reported (Svensson et al. 2008; Tayyebi-Khosroshahi et al. 2012).

In summary, the results of this investigation point to the conclusion that oral supplementation of omega- 3 fatty acids produces significant decreases in the concentrations of inflammation markers in patients with CKD on hemodialysis. Since previous studies on the beneficial effect of omega-3 fatty acid supplementation on cardiovascular risk are contradictory, the present study is extremely important in underlining this positive effect. Thanks to the data provided in this work, we are able to demonstrate that including natural sources or supplements with omega- 3 fatty acids in the regular diets of patients with CKD could improve their general condition. Therefore, it is essential that omega- 3 supplementation become part of the regular protocol of dietary therapy in patients with CKD to improve their quality of life and reduce death rates.

\section{Conflict of interest statement}

We declare that we do not have any conflicts of interest.

\section{Acknowledgements}

The authors gratefully acknowledge the University of Granada for its support for this research. This work fulfills part of the requirements for José Valle's PhD degree.

\section{References}

Abdelhamid, A.S., Brown, T.J., Brainard, J.S., Biswas, P., Thorpe, G.C., Moore, H.J., et al. 2018. Omega-3 fatty acids for the primary and secondary prevention of cardiovascular disease. Cochrane Database Syst. Rev. 11: CD003177. doi:10. 1002/14651858.CD003177.pub4. PMID:30521670.

Barle, H., Hammarqvist, F., Westman, B., Klaude, M., Rooyackers, O., Garlick, P.J., and Wernerman, J. 2006. Synthesis rates of total liver protein and albumin are both increased in patients with an acute inflammatory response. Clin. Sci. (Lond.). 110(1): 93-99. doi:10.1042/CS20050222. PMID: 16144514.

Bossola, M., Leo, A., Viola, A., Carlomagno, G., Monteburini, T., Cenerelli, S., et al. 2013. Dietary intake of macronutrients and fiber in Mediterranean patients on chronic hemodialysis. J. Nephrol. 26(5): 912-918. doi:10.5301/jn. 5000222. PMID:23065914.

Calder, P.C. 2015. Marine omega-3 fatty acids and inflammatory processes: Effects, mechanisms and clinical relevance. Biochim. Biophys. Acta, 1851(4): 469-484. doi:10.1016/j.bbalip.2014.08.010. PMID:25149823.

Calder, P.C. 2017. Omega-3 fatty acids and inflammatory processes: from molecules to man. Biochem. Soc. Trans. 45(5): 1105-1115. doi:10.1042/BST20160474. PMID:28900017.

Dai, L., Golembiewska, E., Lindholm, B., and Stenvinkel, P. 2017. End-stage renal disease, inflammation and cardiovascular outcomes. Contrib. Nephrol. 191: 32-43. doi:10.1159/000479254. PMID:28910789.

Donadio, C., Tognotti, D., and Donadio, E. 2012. Albumin modification and fragmentation in renal disease. Clin. Chim. Acta, 413(3-4): 391-395. doi:10. 1016/j.cca.2011.11.009. PMID:22120732.

Ewers, B., Riserus, U., and Marckmann, P. 2009. Effects of unsaturated fat dietary supplements on blood lipids, and on markers of malnutrition and inflammation in hemodialysis patients. J. Ren. Nutr. 19(5): 401-411. doi:10.1053/j.jrn. 2009.04.006. PMID:19541503.

Fassett, R.G., Gobe, G.C., Peake, J.M., and Coombes, J.S. 2010. Omega-3 polyun- saturated fatty acids in the treatment of kidney disease. Am. J. Kidney Dis. 56(4): 728-742. doi:10.1053/j.ajkd.2010.03.009. PMID:20493605.

Fiedler, R., Mall, M., Wand, C., and Osten, B. 2005. Short-term administration of omega-3 fatty acids in hemodialysis patients with balanced lipid metabolism. J. Ren. Nutr. 15(2): 253-256. doi:10.1053/j.jrn.2005.01.007. PMID:15827899.

Gharekhani, A., Khatami, M.R., Dashti-Khavidaki, S., Razeghi, E., Abdollahi, A., Hashemi-Nazari, S.S., and Mansournia, M.A. 2014. Potential effects of omega-3 fatty acids on anemia and inflammatory markers in maintenance hemodialysis patients. Daru, 22(1): 11. doi:10.1186/2008-2231-22-11. PMID: 24397938 .

Hall, W.L. 2017. The future for long chain n-3 PUFA in the prevention of coronary heart disease: do we need to target non-fish-eaters? Proc. Nutr. Soc. 76(3): 408-418. doi:10.1017/S0029665117000428. PMID:28508737.

Han, E., Yun, Y., Kim, G., Lee, Y.H., Wang, H.J., Lee, B.W., et al. 2016. Effects of omega-3 fatty acid supplementation on diabetic nephropathy progression in patients with diabetes and hypertriglyceridemia. PLoS One, 11(5): e0154683. doi:10.1371/journal.pone.0154683. PMID:27135947.

Hassan, K.S., Hassan, S.K., Hijazi, E.G., and Khazim, K.O. 2010. Effects of omega-3 on lipid profile and inflammation markers in peritoneal dialysis patients. Ren. Fail. 32(9): 1031-1035. doi:10.3109/0886022X.2010.510231. PMID:20863205.

Holm, T., Berge, R.K., Andreassen, A.K., Ueland, T., Kjekshus, J., Simonsen, S., et al. 2001. Omega-3 fatty acids enhance tumor necrosis factor-alpha levels in heart transplant recipients. Transplantation, 72(4): 706-711. doi:10.1097| 00007890-200108270-00025. PMID:11544435.

Inoue, T., Tanaka, M., Masuda, S., Ohue-Kitano, R., Yamakage, H., Muranaka, K., et al. 2017. Omega-3 polyunsaturated fatty acids suppress the inflammatory responses of lipopolysaccharide-stimulated mouse microglia by activating SIRT1 pathways. Biochim. Biophys. Acta Mol. Cell Biol. Lipids, 1862(5): 552560. doi:10.1016/j.bbalip.2017.02.010. PMID:28254441.

Iqbal, T., Stein, J., Sharma, N., Kulnigg-Dabsch, S., Vel, S., and Gasche, C. 2015. Clinical significance of C-reactive protein levels in predicting responsiveness to iron therapy in patients with inflammatory bowel disease and iron deficiency anemia. Dig. Dis. Sci. 60(5): 1375-1381. doi:10.1007/s10620-014-3460-4. PMID:25501922.

Kooshki, A., Taleban, F.A., Tabibi, H., and Hedayati, M. 2011. Effects of marine omega-3 fatty acids on serum systemic and vascular inflammation markers and oxidative stress in hemodialysis patients. Ann. Nutr. Metab. 58(3): 197202. doi:10.1159/000329727. PMID:21757893.

Krintus, M., Kozinski, M., Kubica, J., and Sypniewska, G. 2014. Critical appraisal of inflammatory markers in cardiovascular risk stratification. Crit. Rev. Clin. Lab. Sci. 51(5): 263-279. doi:10.3109/10408363.2014.913549. PMID:24918900.

Labonte, M.E., Dewailly, E., Lucas, M., Couture, P., and Lamarche, B. 2014. Association of red blood cell n-3 polyunsaturated fatty acids with plasma inflammatory biomarkers among the Quebec Cree population. Eur. J. Clin. Nutr. 68(9): 1042-1047. doi:10.1038/ejcn.2014.125. PMID:25028086.

Leypoldt, J.K., Jaber, B.L., and Zimmerman, D.L. 2004. Predicting treatment dose for novel therapies using urea standard Kt/V. Semin. Dial. 17(2): 142-145. doi:10.1111/j.0894-0959.2004.17212.x. PMID:15043617.

Magee, P., Pearson, S., Whittingham-Dowd, J., and Allen, J. 2012. PPAR $\gamma$ as a molecular target of EPA anti-inflammatory activity during TNF- $\alpha$-impaired skeletal muscle cell differentiation. J. Nutr. Biochem. 23(11): 1440-1448. doi: 10.1016/j.jnutbio.2011.09.005. PMID:22305406.

Memoli, B., Minutolo, R., Bisesti, V., Postiglione, L., Conti, A., Marzano, L., et al. 2002. Changes of serum albumin and C-reactive protein are related to changes of interleukin- 6 release by peripheral blood mononuclear cells in hemodialysis patients treated with different membranes. Am. J. Kidney Dis. 39(2): 266-273. doi:10.1053/ajkd.2002.30545. PMID:11840366.

Memoli, B., Salerno, S., Procino, A., Postiglione, L., Morelli, S., Sirico, M.L., et al. 2010. A translational approach to micro-inflammation in end-stage renal disease: molecular effects of low levels of interleukin-6. Clin. Sci. (Lond.). 119(4): 163-174. doi:10.1042/CS20090634. PMID:20380647.

Moertl, D., Hammer, A., Steiner, S., Hutuleac, R., Vonbank, K., and Berger, R. 2011. Dose-dependent effects of omega-3-polyunsaturated fatty acids on systolic left ventricular function, endothelial function, and markers of inflammation in chronic heart failure of nonischemic origin: a double-blind, placebo-controlled, 3-arm study. Am. Heart J. 161(5): 915.e1-915.e9. doi:10.1016/ j.ahj.2011.02.011. PMID:21570522.

Rasic-Milutinovic, Z., Perunicic, G., Pljesa, S., Gluvic, Z., Sobajic, S., Djuric, I., and Ristic, D. 2007. Effects of N-3 PUFAs supplementation on insulin resistance and inflammatory biomarkers in hemodialysis patients. Ren. Fail. 29(3): 321329. doi:10.1080/08860220601184092. PMID:17497447.

Rivara, M.B., Ikizler, T.A., Ellis, C.D., Mehrotra, R., and Himmelfarb, J. 2015. Association of plasma F2-isoprostanes and isofurans concentrations with erythropoiesis-stimulating agent resistance in maintenance hemodialysis patients. BMC Nephrol. 16: 79. doi:10.1186/s12882-015-0074-9. PMID:26045064.

Sabry, A.A., Elshafey, E.M., Alsaran, K., Shalaby, M., Alsherbeiny, S., and Abdelkader, M. 2014. The level of C-reactive protein in chronic hemodialysis patients: a comparative study between patients with noninfected catheters and arteriovenous fistula in two large Gulf hemodialysis centers. Hemodial. Int. 18(3): 674-679. doi:10.1111/hdi.12145. PMID:24467342.

Saifullah, A., Watkins, B.A., Saha, C., Li, Y., Moe, S.M., and Friedman, A.N. 2007. Oral fish oil supplementation raises blood omega-3 levels and lowers 
C-reactive protein in haemodialysis patients-a pilot study. Nephrol. Dial. Transplant. 22(12): 3561-3567. doi:10.1093/ndt/gfm422. PMID:17623719.

Sarav, M., and Friedman, A.N. 2018. Use of intradialytic parenteral nutrition in patients undergoing hemodialysis. Nutr. Clin. Pract. 33(6): 767-771. doi:10. 1002/ncp.10190. PMID:30207411.

Šulović, L.S. 2017. Risk factors for cardiovascular disease in children on chronic hemodialysis - Uremia related (non-traditional) risk factors, part II. Vojnosanit. Pregl. 74(1): 54-58. doi:10.2298/VSP150418144S. PMID:29350892.

Svensson, M., Schmidt, E.B., Jorgensen, K.A., and Christensen, J.H. 2008. The effect of n-3 fatty acids on lipids and lipoproteins in patients treated with chronic haemodialysis: a randomized placebo-controlled intervention study. Nephrol. Dial. Transplant. 23(9): 2918-2924. doi:10.1093/ndt/gfn180. PMID: 18436564.

Tayyebi-Khosroshahi, H., Houshyar, J., Dehgan-Hesari, R., Alikhah, H.,
Vatankhah, A.M., Safaeian, A.R., and Zonouz, N.R. 2012. Effect of treatment with omega-3 fatty acids on C-reactive protein and tumor necrosis factor-alfa in hemodialysis patients. Saudi J. Kidney Dis. Transpl. 23(3): 500-506. PMID: 22569435.

Wakasugi, M., Kazama, J.J., and Narita, I. 2016. Mortality trends among Japanese dialysis patients, 1988-2013: a joinpoint regression analysis. Nephrol. Dial. Transplant. 31(9): 1501-1507. doi:10.1093/ndt/gfw249. PMID:27402812.

Wang, T., He, X., Liu, X., Liu, Y., Zhang, W., Huang, Q., et al. 2017. Weighted gene co-expression network analysis identifies FKBP11 as a key regulator in acute aortic dissection through a NF-kB dependent pathway. Front. Physiol. 8: 1010. doi:10.3389/fphys.2017.01010. PMID:29255427.

Watkins, B.A., Kim, J., Tamez, H., Wenger, J., Thadhani, R., and Friedman, A.N. 2016. Serum phospholipid fraction of polyunsaturated fatty acids is the preferred indicator for nutrition and health status in hemodialysis patients. J. Nutr. Biochem. 38: 18-24. doi:10.1016/j.jnutbio.2016.07.021. PMID:27721114. 